\title{
Interactive comment on "Proximate and underlying drivers of socio-hydrologic change in the upper Arkavathy watershed, India" by Veena Srinivasan et al.
}

\section{Veena Srinivasan et al.}

veena.srinivasan@gmail.com

Received and published: 18 March 2018

Reviewer 3, Christopher Scott, has been largely supportive and has only asked for technical revisions. offered a number of specific comments including wording and punctuation changes. We thank the reviewer for his careful reading. These will be incorporated in the rewriting. In this response, we only address the substantive comments.

A point by point response is provided in the supplementary .pdf. 
https://www.hydrol-earth-syst-sci-discuss.net/hess-2017-543/hess-2017-543-AC3supplement.pdf

Interactive comment on Hydrol. Earth Syst. Sci. Discuss., https://doi.org/10.5194/hess-2017-

543, 2017.

Interactive

comment 